\title{
Therapeutic Effect of Microcurrent Therapy in Children With In-toeing Gait Caused by Increased Femoral Anteversion: A Pilot Study
}

\author{
Jae Ki Ahn, MD, PhD ${ }^{1}$, Dong Rak Kwon, MD, PhD ${ }^{2}$, Gi-Young Park, MD, PhD'², \\ Ki-Hoon Lee, $\mathrm{MD}^{1}$, Jae Hwal Rim, $\mathrm{MD}^{2}$, Won Bin Jung, $\mathrm{MD}^{2}$, Dae Gil Kwon, $\mathrm{MD}^{2}$ \\ ${ }^{1}$ Department of Rehabilitation Medicine, Inje University Sanggye Paik Hospital, Seoul; \\ ${ }^{2}$ Department of Rehabilitation Medicine, Catholic University of Daegu School of Medicine, Daegu, Korea
}

\begin{abstract}
Objective To investigate the efficacy of portable microcurrent therapy device (PMTD) of the hip internal rotators in the treatment of in-toeing gait caused by increased femoral anteversion in children over 8 years of age. Methods Eleven children (22 legs; 4 boys and 7 girls; mean age, 10.4 \pm 1.6 years) with in-toeing gait caused by increased femoral anteversion were included in the present study. All children received 60 minutes of PMTD (intensity, $25 \mu \mathrm{A}$; frequency, $8 \mathrm{~Hz}$ ) applied to the hip internal rotators daily for 4 weeks. Hip internal rotation (IR) angle, external rotation (ER) angle, and midmalleolar-second toe angle (MSTA) measurement during stance phase at transverse plane and Family Satisfaction Questionnaire, frequency of tripping and fatigue like pains about the PMTD were performed before treatment and at 4 weeks after initial PMTD treatment. Paired t-test and Fisher exact test were used for statistical analysis.

Results Hip IR/ER/MSTA was $70.3^{\circ} \pm 5.4^{\circ} / 20.1^{\circ} \pm 5.5^{\circ} /-11.4^{\circ} \pm 2.7^{\circ}$, and $55.7^{\circ} \pm 7.8^{\circ} / 33.6^{\circ} \pm 8.2^{\circ} /-2.6^{\circ} \pm 3.8^{\circ}$ before treatment and at 4 weeks after initial PMTD treatment, respectively $(\mathrm{p}<0.01)$. Ten of $11(91 \%)$ children's family stated that they were generally satisfied with the PMTD treatment. The frequency of tripping and fatigue like pains was significantly lower at 4 weeks after PMTD treatment $(\mathrm{p}<0.05)$. Excellent inter-rater and intra-rater reliability was observed for repeated MSTA measurements between the examiners ( $\mathrm{k}=0.91-0.96$ and $\mathrm{k}=0.93-0.99)$, respectively.

Conclusion PMTD of the hip internal rotators can be effective in improving the gait pattern of children with intoeing gait caused by increased femoral anteversion.
\end{abstract}

Keywords Bone anteversion, Gait, Electrical stimulation therapy

Received April 28, 2016; Accepted August 2, 2016

Corresponding author: Dae Gil Kwon

Department of Rehabilitation Medicine, Catholic University of Daegu School of Medicine, 33 Duryugongwon-ro 17-gil, Nam-gu, Daegu 42472, Korea. Tel: +82-53-650-4894, Fax: +82-53-622-4687, E-mail: cateyesn@naver.com

ORCID: Jae Ki Ahn (http://orcid.org/0000-0002-1728-181X); Dong Rak Kwon (http://orcid.org/0000-0003-4728-930X); Gi-Young Park (http://orcid. org/0000-0003-0056-1556); Ki-Hoon Lee (http://orcid.org/0000-0001-7445-832X); Jae Hwal Rim (http://orcid.org/0000-0002-4176-3253); Won Bin Jung (http://orcid.org/0000-0002-4660-0816); Dae Gil Kwon (http://orcid.org/0000-0002-8423-8045).

(a) This is an open-access article distributed under the terms of the Creative Commons Attribution Non-Commercial License (http://creativecommons.org/ licenses/by-nc/4.0) which permits unrestricted noncommercial use, distribution, and reproduction in any medium, provided the original work is properly cited. Copyright $\odot 2017$ by Korean Academy of Rehabilitation Medicine 


\section{INTRODUCTION}

In-toeing gait is a common problem observed during childhood with a prevalence of up to $7 \%$ in children aged 9 years and above [1], and is defined by the presence of an internal foot progression angle [2]. In-toeing gait results from static anatomical malalignments such as increased femoral anteversion, internal tibial torsion, and metatarsus adductus [3]. Increased femoral anteversion is the main cause of in-toeing in approximately $70 \%$ of children older than 2 years [4]. Although in-toeing gait usually corrects itself before 8 years of age [5], this condition sometimes produces functional problems such as frequent tripping. In addition, the long-term effect of intoeing gait pattern such as patella-femoral pathology, hip joint arthrosis, and patella instability has been cited within the literature [6].

Increased femoral anteversion angle is defined as an increased angle at the intersection of an imaginary transverse line that runs medially through the knee joint and an imaginary transverse line passing through the centre of the femoral head and neck $[7,8]$. Muscle, either by its contractile force or by its passive elastic connective tissue, contributes towards the greatest torsional stress on bone [9].

Previous study has indicated a significant association between internal rotation range of motion and femoral anteversion [10]. Crane found that children with increased femoral anteversion angle had internal rotation of the hip exceeding $60^{\circ}[5]$.

Previous animal and human studies suggested that uneven hip muscle forces could produce changes in the femoral neck $[11,12]$. A previous study [11] reported that the femoral neck angle increased when the hind limbs of animals were held fixed in medial rotation. Maintaining internal rotation of the hip posture produces changes in the soft connective tissue surrounding the hip, shortening the hip joint capsule and muscles (tensor fascia lata, gluteus minimus, and anterior fiber of gluteus medius) on the internal rotation side and lengthening the hip joint capsule and muscles on the external rotation side. These asymmetrical changes in soft tissue around the hip place uneven torsional forces on the femur. Previous studies [3,13-15] have shown that asymmetry in hip rotation is often associated with osteoarthritis of the hip, lower back pain, sacroiliac joint dysfunction, as well as patellofemoral pain. In-toeing gait caused by increased femoral anteversion angle is practically seldom caused by foot problems. Nevertheless, in-toeing gait in many children is treated by having the children wear special shoes or other more elaborate devices with weak evidence base $[16,17]$.

Therefore, therapeutic interventions aimed at restoring symmetry in hip muscles can be effective, because differences between the medial rotations of the hip are related to exacerbate femoral anteversion [18].

Microcurrent therapy works at the microampere level and mimics the electrical intensity found in living tissue $[19,20]$. Our previous studies $[21,22]$ demonstrated that in infants with congenital muscular torticollis, microcurrent therapy improves the range of motion of the neck since the therapeutic effect of microcurrent therapy is likely related to increase in the numbers of sarcomeres and adenosine triphosphate (ATP) production, thereby improving contractility as keeping a muscle in a shortened position is a disadvantage because of the decrease in the number of sarcomeres in the muscle cells $[23,24]$.

However, to the best of our knowledge, no previous study has attempted to restore hip muscle symmetry in children with in-toeing gait caused by increased femoral anteversion angle using the presented mechanism. Portable microcurrent therapy device (PMTD) of the hip internal rotator muscles using a surface electrode during walking has never been reported as a management option in children over 8 years of age with in-toeing gait caused by increased femoral anteversion angle. Accordingly, the aim of this study was to investigate the efficacy of PMTD therapy of the hip internal rotators in children with in-toeing gait caused by increased femoral anteversion angle.

\section{MATERIALS AND METHODS}

\section{Participants}

This study was approved by the Institutional Review Board and Ethics Committee of Inje University Sanggye Paik Hospital. Parents provided written permission for their child's participation in the study after receiving an explanation of the research.

Children with in-toeing gait who visited the outpatient clinic of the university hospital were included in this study if they met the following criteria: (1) hip internal 
rotation $\geq 60^{\circ}$ and trochanteric prominence angle $\geq 20^{\circ}$ $[2,8,18]$, (2) bilateral involvement, (3) age over 8 years, (4) symptoms, frequent tripping and fatigue like pains, (5) symptom duration $\geq 1$ year, and (6) no effect from previous rehabilitation therapy such as gait plate and home stretching programs, received for at least an year prior to participation in this study. For trochanteric prominence angle measurement, children's knees were flexed to $90^{\circ}$ in prone position. The examiner palpated the greater trochanter with one hand; while the other hand internally rotated the hip. At the point of maximum trochanteric prominence palpation, representing the most lateral position of the trochanter, the neck of the femur was parallel to the floor. The angle that the tibia formed with the vertical line was measured.

The exclusion criteria were: (1) internal tibial torsion (thigh-foot angle of $<0^{\circ}[8,25]$ ), (2) metatarsus adductus (adduction of the forefoot without varus was clinically assessed), (3) injury or surgery of the lower limb, (4) serious deformities of the lower limb that would affect gait, and (5) neurodevelopmental disorders, such as cerebral palsy or intellectual disability. For the thigh-foot angle, the angle formed by each line that divides the longitudinal axis of the thigh and calcaneus was measured in prone position with the knees bent $90^{\circ}$ and the ankle in the neutral position using goniometer. The negative value refers to the internal rotation of the tibia whereas the positive value refers to the external rotation.

\section{Microcurrent therapy}

All children were treated with a small and portable microcurrent therapy device (intensity, $25 \mu \mathrm{A}$; frequency, $8 \mathrm{~Hz}$; Granthe, Cosmic Co., Seoul, Korea) measuring 90 $\mathrm{mm}(\mathrm{H}) \times 52 \mathrm{~mm}(\mathrm{~W}) \times 19 \mathrm{~mm}(\mathrm{~T})$, weight $49 \mathrm{~g}$ for $60 \mathrm{~min}$ utes daily for 4 weeks. This level of current intensity was significantly below each child's threshold of sensation. The PMTD generator was programmed to provide an alternating current characterised by a monophasic rectangular pulse format with polarity reversal every 2 seconds. For each subject, the electrical patches for PMTD therapy were attached at the fixed point of the internal rotators, which was located at the middle of two reference points and greater trochanter (Fig. 1). One point was located at the medial one-sixth of the longitudinal line between the distance from the anterior superior iliac spine and posterior superior iliac spine along the outer lip of the iliac

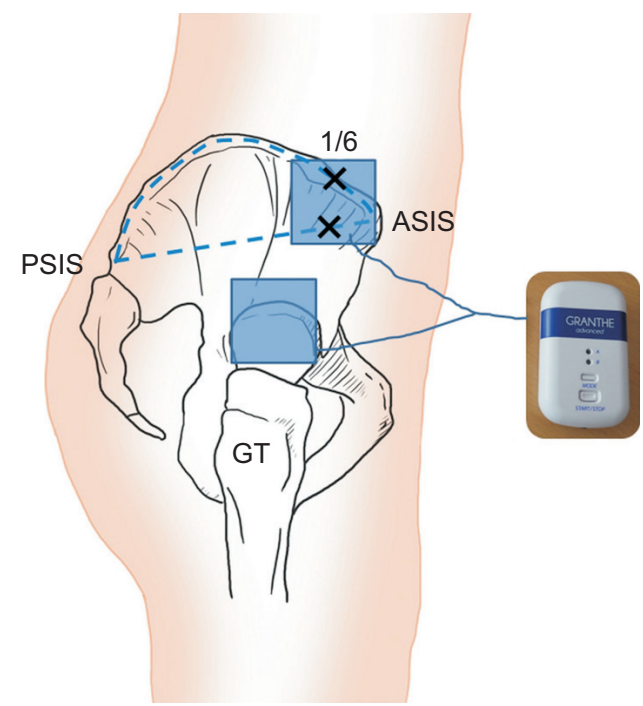

Fig. 1. The electrical patches for microcurrent therapy were attached at the fixed point of the anterior fibres of the gluteus medius and minimus muscles, which were located at the middle of two reference points and greater trochanter (GT). PSIS, posterior superior iliac spine; ASIS, anterior superior iliac spine.

crest, and the other point was located at the medial onesixth of the longitudinal line between the direct distance from anterior superior iliac spine and posterior superior iliac spine. These locations were directed to the children's internal rotators including gluteus minimus and anterior fiber of gluteus medius, $1.0 \mathrm{~cm}$ toward the greater trochanter, according to previously verified guidelines [26].

This protocol included a home-based program of 60 minutes per day of bilateral continuous electrical stimulation of the hip internal rotation muscles during walking. Parents were taught how to use PMTD. To simplify the procedure and to guide the parents about the appropriate position of the PMTD electrodes, two small rectangles were drawn with a pen over the hip internal rotation muscles bilaterally. The PMTD unit was adjusted and fixed to the selected parameters and its use was demonstrated to the parents in the gait laboratory. Parents were given the following instructions: (1) expose the target area on both the hips and ask your child to sit comfortably on the floor or a chair, (2) clean the target areas with a moist alcohol swab or warm wet towel, (3) place the self-adhesive electrodes over the rectangular area on both the sides with the active electrode (marked red-line) 
over the belly of the muscle (rectangular 1) and the other electrode (marked blue-line) $1 \mathrm{~cm}$ lower the belly of the muscle (rectangular 2), (4) turn the PMTD unit on, (5) ask your child to stand and walk by him/herself at the selected speed for 60 minutes, (6) after that, ask your child to sit on the floor or a chair and then turn off the PMTD, and (7) repeat this once daily for 4 weeks.

\section{Clinical measurements}

Each patient underwent a before treatment physical examination, including passive range of motion tests. At the time of measuring hip rotation, patients were placed in the prone position on a firmly padded treatment table. The knee was flexed to $90^{\circ}$ [27], and the legs were bent by gravity, without an external force, to measure the angle [28]. The examiner (KDR) stopped the leg at the end of passive range of motion when a firm end-feel was noted. The movement arm of the goniometer was aligned vertically along the shaft of the tibia. The examiner was blinded to the amount of movement measured by the goniometer; measurements were read and recorded by a different examiner (KDG). A previous study [25] using this method reported a correlation coefficient of interrater reliability of 0.739 and 0.824 for the measurement of hip internal rotation in children with in-toeing gait. Clinical measurements were performed before treatment and at 4 weeks after initial treatment.

The questionnaire consisting of family's satisfaction about the PMTD were performed at 4 weeks after initial PMTD treatment. Questionnaire consisted of three categories involving assessment of satisfaction, frequency of tripping, and fatigue like pains. In the first part, the families were asked to rate their overall satisfaction level and to state their willingness to retreat or recommend the PMTD to others. The subjective rating reflected the opinion of the family. The results of the subjective rating were unknown to the examiner at the time of clinical assessment. The frequency of tripping and fatigue like pains were recorded before treatment and at 4 weeks after PMTD treatment.

\section{Video editing and analysis}

Motion capture using video has been widely used in physical and rehabilitation medicine to evaluate walking ability of patients. Criteria for inclusion of a video in this study were as follows: (1) good quality, with the cam- era angle approximating an anterior view of the patient and (2) visualization of the foot contacting the ground. The video recordings were replayed and edited using Adobe Premiere Pro v2.0 (Adobe Systems, San Jose, CA, USA) and deinterlaced to achieve a $30-\mathrm{Hz}$ (frame/s) effective frame rate via Adobe Photoshop v.CS2, (Adobe Systems) [29]. The joint kinematics was measured from the video sequences by two blinded examiners using ImageJ software (National Institutes of Health, Bethesda, MD, USA). Midmalleolar-second toe angle (MSTA) was defined as the angle between the two reference lines in the transverse plane (one line was an imaginary line drawn perpendicular to the midway between the medial and lateral malleoli; and the other line was an imaginary longitudinal line drawn from midway between the medial and lateral malleoli to the second toe) and measured from anterior views of motion capture by ImageJ. MSTA value can reflect the degree of foot progression angle. The mean MSTAs were analysed in five sequential frames (stored as TIFF files) during stance phase at transverse plane, starting with midstance (time 0 ), so that the time sequences observed were at approximate midstance of the foot with the floor and 50, 100, 150, and $200 \mathrm{~ms}$ (Fig. 2). All measurements were performed twice by two different examiners (A, physical therapist; B, physiatrist) before PMTD treatment and at 4 weeks after initial PMTD treat-

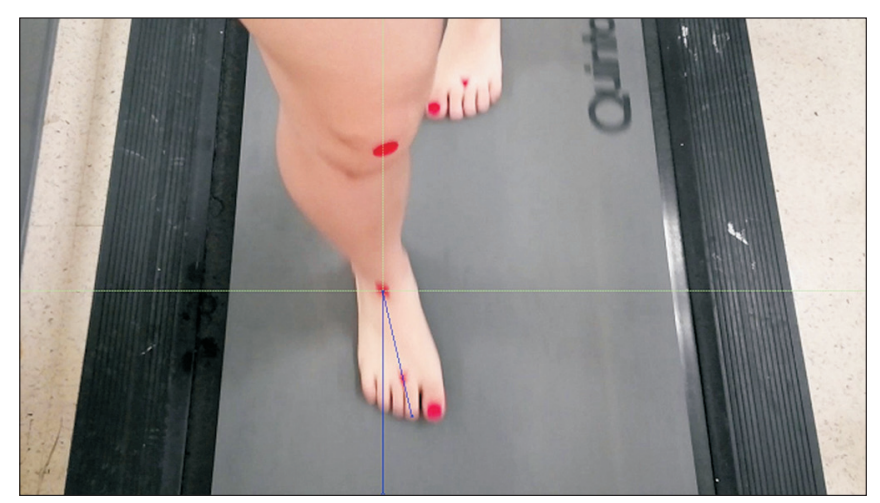

Fig. 2. Still image of a girl in-toeing gait demonstrating midmalleolar-second toe angle (MSTA), which is defined as the angle between the two reference lines in the transverse plane (one line was an imaginary line drawn perpendicular to the midway between the medial and lateral malleoli; the other line was an imaginary longitudinal line drawn from midway between the medial and lateral malleoli to second toe) and calculated using still image of gait motion analysis. 
ment. Five sequential frames from each video were used to determine the intra-rater and inter-rater reliability of the mean MSTA measurements.

Statistical analysis was performed using the Statistical Package for the Social Sciences (SPSS) ver. 19.0 (IBM, Armonk, NY, USA) with a level of significance of $<0.05$. Data are presented as mean and standard deviation. Paired ttest was used to measure differences in hip internal rotation and MSTA between before treatment and 4 weeks after initial PMTD treatment. Fisher exact test was used for comparison of the frequency of tripping and fatigue like pains between before treatment and at 4 weeks after PMTD treatment. The intraclass correlation coefficients (ICCs) were calculated to assess the intra-rater and interrater reliability of the repeated MSTA measurements at each video frame sequence at two different times. ICC were classified as excellent $(>0.75)$, fair to good $(0.44-$ $0.75)$, and poor $(<0.44)[30]$.

\section{RESULTS}

Eleven children ( 4 boys and 7 girls; mean age, 10.4 \pm 1.6 years; 22 legs, 8 legs for boy and 14 legs for girl) were included in the present study. The mean age of the children was $10.4 \pm 1.6$ years, the girl to boy ratio was $1.7: 1$, and the mean treatment duration of previous rehabilitation therapy was $29.9 \pm 16.7$ months (Table 1 ).

Hip internal rotation was $70.3^{\circ} \pm 5.4^{\circ}$ and $55.7^{\circ} \pm 7.8^{\circ}$ before treatment and at 4 weeks after initial PMTD treatment, respectively $(\mathrm{p}<0.01)$. Hip external rotation was $20.1^{\circ} \pm 5.5^{\circ}$ and $33.6^{\circ} \pm 8.2^{\circ}$ before treatment and at 4 weeks after initial PMTD treatment, respectively ( $<<0.01)$. MSTA was $-11.4^{\circ} \pm 2.7^{\circ}$ and $-2.6^{\circ} \pm 3.8^{\circ}$ before PMTD treatment and at 4 weeks after initial PMTD treatment, respectively $(\mathrm{p}<0.01)$ (Tables 2, 3).

Table 1. Demographic data

\begin{tabular}{lc}
\hline \multicolumn{1}{c}{ Characteristic } & Value \\
\hline Age (yr) & $10.4 \pm 1.6$ \\
Sex & $4(36.4)$ \\
Boy & $7(63.6)$ \\
Girl & $29.9 \pm 16.7$ \\
\hline Duration of previous treatment (mo)
\end{tabular}

Values are presented as mean \pm standard deviation or number (\%).
On the question of overall satisfaction and the willingness of parents to retreat or recommend the PMTD treatment to others, 7 of the parents $(63.6 \%)$ answered that they were 'very satisfied', $3(27.2 \%)$ and $1(0.9 \%)$ responded that they were 'satisfied' and 'neither satisfied or dissatisfied,' respectively.

The frequency of tripping and fatigue like pains was significantly lower at 4 weeks after PMTD treatment $(\mathrm{p}<0.05)$ (Table 4).

Excellent inter-rater reliability was found for repeated MSTA measurements between the examiners ( $\mathrm{k}=0.91-$ 0.96). Furthermore, the intra-rater reliability was observed to be excellent $(k=0.93-0.99)$.

\section{DISCUSSION}

The mean value of internal rotation at age of 10 is about $50^{\circ}$ [18]. Our study revealed that the mean hip internal rotation, external rotation, and MSTA values were significantly improved at 4 weeks after initial PMTD treatment in children with in-toeing gait caused by increased femoral anteversion angle. Significant decrease in hip internal rotation after PMTD treatment could be attributed to decreased femoral anteversion angle since hip internal rotation is associated with femoral version. Consequently, improvement in MSTA value was noted due to decrease in the femoral anteversion angle. Therapeutic mechanism by which microcurrent affects shortened muscle remains unknown. However, there are speculated explanations for the improvement in hip internal rotation and MSTA values in children with in-toeing gait caused by increased femoral anteversion angle. First, the therapeutic effect is likely related to the mechanical pressure of microcurrent. Shortened muscle revealed decrease in the number of available cross-bridge formations between actin and myosin filaments and the number of sarcomeres in the muscle cells [23,31]. Mechanical signals, which are vital for normal tissue metabolism, could be replaced by electrical signals, because they produce oscillatory forces and vibration in the tissue [32]. Therefore, electrical stimulation has been reported to produce an increase in the numbers of sarcomeres, thereby improving contractility [33].

Second, it is also suggested that microcurrent therapy might increase the synthesis of ATP and protein as well as amino acid transportation [34]. Microcurrent stimulation 
Table 2. Effect of microcurrent stimulation on passive IR, ER, and MSTA

\begin{tabular}{|c|c|c|c|c|c|c|c|}
\hline \multirow{2}{*}{$\begin{array}{c}\text { Patient } \\
\text { no. }\end{array}$} & \multirow{2}{*}{ Age/sex } & \multirow{2}{*}{$\begin{array}{c}\text { Treatment } \\
\text { duration }(\mathrm{mo})\end{array}$} & \multirow{2}{*}{ Side } & \multicolumn{2}{|c|}{ MSTA } & \multicolumn{2}{|c|}{ IR/ER } \\
\hline & & & & Pre & Post & Pre & Post \\
\hline \multirow[t]{2}{*}{1} & $11 / \mathrm{M}$ & 16 & $\mathrm{R}$ & -7.6 & 5.0 & $70 / 18$ & $45 / 45$ \\
\hline & & & $\mathrm{L}$ & -6.6 & 3.8 & $70 / 20$ & $48 / 40$ \\
\hline \multirow[t]{2}{*}{2} & $8 / F$ & 42 & $\mathrm{R}$ & -12.6 & 2.9 & $75 / 15$ & $68 / 20$ \\
\hline & & & $\mathrm{L}$ & -11.2 & -6.8 & $82 / 10$ & $70 / 25$ \\
\hline \multirow[t]{2}{*}{3} & $11 / \mathrm{F}$ & 18 & $\mathrm{R}$ & -12.5 & -6.5 & $60 / 20$ & $55 / 40$ \\
\hline & & & $\mathrm{L}$ & -12.6 & -4.9 & $70 / 20$ & $52 / 45$ \\
\hline \multirow[t]{2}{*}{4} & $10 / \mathrm{F}$ & 36 & $\mathrm{R}$ & -13.4 & -1.0 & $72 / 20$ & $40 / 38$ \\
\hline & & & $\mathrm{L}$ & -16.6 & -4.0 & $68 / 25$ & $40 / 42$ \\
\hline \multirow[t]{2}{*}{5} & $11 / \mathrm{F}$ & 24 & $\mathrm{R}$ & -16.2 & -7.7 & $60 / 22$ & $55 / 44$ \\
\hline & & & $\mathrm{L}$ & -12.1 & -6.1 & $70 / 22$ & $52 / 40$ \\
\hline \multirow[t]{2}{*}{6} & $11 / \mathrm{F}$ & 33 & $\mathrm{R}$ & -13.9 & -4.9 & $77 / 13$ & $61 / 28$ \\
\hline & & & $\mathrm{L}$ & -9.5 & -6.0 & $75 / 15$ & $55 / 33$ \\
\hline \multirow[t]{2}{*}{7} & $9 / \mathrm{F}$ & 12 & $\mathrm{R}$ & -12.5 & -4.4 & $67 / 23$ & $56 / 23$ \\
\hline & & & $\mathrm{L}$ & -12.3 & -3.1 & $65 / 25$ & $55 / 26$ \\
\hline \multirow[t]{2}{*}{8} & $10 / \mathrm{M}$ & 70 & $\mathrm{R}$ & -10.1 & -1.9 & $68 / 30$ & $54 / 45$ \\
\hline & & & $\mathrm{L}$ & -11.0 & -5.8 & $72 / 17$ & $59 / 30$ \\
\hline \multirow[t]{2}{*}{9} & $10 / \mathrm{M}$ & 33 & $\mathrm{R}$ & -7.0 & -0.6 & $70 / 25$ & $60 / 30$ \\
\hline & & & $\mathrm{L}$ & -10.8 & -3.0 & $70 / 20$ & $66 / 22$ \\
\hline \multirow[t]{2}{*}{10} & $9 / \mathrm{M}$ & 13 & $\mathrm{R}$ & -13.0 & 1.0 & $67 / 28$ & $57 / 33$ \\
\hline & & & $\mathrm{L}$ & -13.3 & -6.7 & $65 / 28$ & $55 / 35$ \\
\hline \multirow[t]{2}{*}{11} & $14 / F$ & 32 & $\mathrm{R}$ & -7.0 & 3.2 & $77 / 12$ & $63 / 27$ \\
\hline & & & $\mathrm{L}$ & -10.3 & -1.2 & $77 / 13$ & $60 / 27$ \\
\hline
\end{tabular}

IR, internal rotation; ER, external rotation; MSTA, midmalleolar-second toe angle; R, right; L, left.

Table 3. Outcome measures at before and 4 weeks after PMTD treatment

\begin{tabular}{lrcc}
\hline & \multicolumn{2}{c}{ PMTD } & p-value \\
\cline { 2 - 3 } & Pre & Post & \\
\hline MSTA & $-11.4 \pm 2.7$ & $-2.6 \pm 3.8$ & $<0.01^{*}$ \\
IR & $70.3 \pm 5.4$ & $55.7 \pm 7.8$ & $<0.01^{*}$ \\
ER & $20.1 \pm 5.5$ & $33.6 \pm 8.2$ & $<0.01^{*}$ \\
\hline
\end{tabular}

Values are presented as mean \pm standard deviation.

PMTD, portable microcurrent therapy device; MSTA, midmalleolar-second toe angle; IR, internal rotation; ER, external rotation.

${ }^{*} \mathrm{p}<0.01$ by paired $\mathrm{t}$-test.

creates mild pressure waves in the tissue and can thus affect the extracellular matrix of the cells. Since the matrix molecules are in contact with the cell-membrane mechanosensitive receptors, the stimulation spreads through them towards the cytoskeleton. Many cell organelles and enzymes are activated inside the cell. Consequently,
Table 4. Changes in frequency of tripping and fatigue like pains between at before and 4 weeks after PMTD treatment

\begin{tabular}{lccc}
\hline & \multicolumn{2}{c}{ PMTD } & \\
\cline { 2 - 3 } & Pre & Post & p-value \\
\hline Frequency of tripping & & & $0.024^{*}$ \\
$\quad \geq 3$ & $7(63.6)$ & $1(9.9)$ & \\
$\quad<3$ & $4(36.4)$ & $10(90.1)$ & \\
$\begin{array}{l}\text { Frequency of fatigue } \\
\text { like pain }\end{array}$ & & $0.008^{*}$ \\
$\quad \geq 3$ & & & \\
$<3$ & $8(72.7)$ & $1(9.9)$ & \\
\hline
\end{tabular}

Values are presented as number (\%).

PMTD, portable microcurrent therapy device.

${ }^{*} \mathrm{p}<0.05$ by Fisher exact test.

there may be an increase in ATP production and in the release of trophic factors affecting protein synthesis. During normal muscular rest, the actin and myosin overlap 
to some extent. These thick and thin filaments are able to slide over each other and the phenomenon is achieved by brief attachment of the cross-bridges of the myosin to actin, while propelling the myosin along the actin in the presence of ATP [35]. Skeletal muscle uses chemical energy in the form of ATP to fuel the contractile apparatus. As shortened muscle may not develop maximal tension if the resting length has been altered, weakness of skeletal muscle apparently reduces ATP production [36]. The beneficial effects of electric current on soft tissue repair have been described previously [37].

In this study, the frequency of tripping and fatigue like pains was significantly lower at 4 weeks after PMTD treatment. Ten of 11 (91\%) children's family stated that they were generally satisfied with the PMTD treatment. Maintaining an internal rotation of the hip posture leads to shortening of the hip muscles on the internal rotation side. Therefore, we selected the internal rotator for PMTD therapy since restoring symmetry in the hip muscles is a reasonable approach to treat in-toeing gait [18].

The level of microcurrent intensity used in the present study was significantly below the children's threshold of sensation, and they reported feeling nothing during microcurrent therapy. As expected, there were no adverse effects or untoward events, because microcurrent stimulation works at the microampere level and mimics the electrical intensity found in living tissue $[19,20]$.

Similar to other electrotherapies, the outcome of microcurrent therapy is parameter dependent. Previous study [38] has used 10-50 $\mu \mathrm{A}$ amplitude of microcurrent to treat muscle-related problems, although different microcurrent machines were used. The employed current intensities are within the range that has been found to be optimum for ATP generation. The reported data are in agreement with the findings of this study and suggest that low-amperage currents increase tissue regeneration. Different frequencies are considered effective in the treatment of specific conditions. In our study, the frequency was set at $8 \mathrm{~Hz}$. Previous studies $[34,35]$ conducted with $10 \mathrm{~Hz}$ frequency have reported the potential of microcurrent to enhance microcirculation in the treatment of muscle-related problems. Previous studies $[37,38]$ have demonstrated low frequencies to be more efficient in promoting the repair of connective tissues, as they act by altering the membrane potentials of the cell. Our animal study (unpublished data) using PMTD (intensity, $25 \mu \mathrm{A}$; frequency, $8 \mathrm{~Hz}$ ) showed that electrical stimulation with PMTD for 60 minutes daily for 1 week has a possibility of reducing the degree of muscle atrophy (immobilization+PMTD group $\mathbf{8 \% - 1 0 \%}$ vs. immobilized group 26\%-33\%) in cast-induced immobilization rabbit model. These parameters can also be applied to the present study.

In this study, we defined MSTA and selected 2nd toe as the anterior mark for the foot bisection. This result is in agreement with a previous study [39], which demonstrated that the centre of the 2nd toe was used as the anterior marking point for the foot bisection line in foot progression angle, as it was the most reliable point for measurement. The degree of in-toeing can be determined using the foot progression angle [40]. Therefore, it is proposed that MSTA can also serve as an instrument to determine the therapeutic success of the treatment of rotational deformities by comparison with the previous measurements, which can easily be recorded, since repeated MSTA measurements at each video frame sequence demonstrated high reproducibility in the present study.

In our study, we chose the PMTD stimulation for 4 weeks since our previous clinical experience demonstrated that a time period of this duration is well tolerated by the children and their families.

Our study also has some limitations. First, the main limitation of our study was the lack of controls. In order to overcome the drawbacks of not adopting a casecontrolled design, we assumed that there were no effects from previous rehabilitation therapy such as gait plate and home stretching programs, received at least a year prior to participation in this study. In the near future, a randomized controlled study is needed. Second, we could not determine the influence of different underlying pathologies, either structural or postural, as an extensive assessment of imaging studies was not performed. Third, the number of subjects was small, and further investigation with a larger population is needed to assess the usefulness of microcurrent therapy as a treatment for in-toeing gait caused by increased femoral anteversion angle. Fourth, because we did not perform physical therapy, further study is needed to evaluate the combined effect of microcurrent therapy and physical therapy. Fifth, considering that this study was conducted in a relatively short time period, additional studies must be performed to assess long-term effects. Lastly, additional studies are 
needed to evaluate the effects of microcurrent therapy at different current intensity, frequency, and treatment duration at which the therapy is started for achievement of paramount and extremely reliable results.

In conclusion, the results of this pilot study show that PMTD may have the potential to improve the gait pattern in children with an in-toeing gait pattern caused by increased femoral anteversion angle by treating the hip internal rotators.

\section{CONFLICT OF INTEREST}

No potential conflict of interest relevant to this article was reported.

\section{ACKNOWLEDGMENTS}

This research was supported by Basic Science Research Program through the National Research Foundation of Korea (NRF) funded by the Ministry of Education (NRF2016R1D1A1B01014260).

\section{REFERENCES}

1. Thackeray C, Beeson P. Is in-toeing gait a developmental stage? Foot 1996;6:19-24.

2. Staheli LT, Corbett M, Wyss C, King H. Lower-extremity rotational problems in children: normal values to guide management. J Bone Joint Surg Am 1985;67:3947.

3. Winter WG Jr, Lafferty JF. The skiing sequelae of tibial torsion. Orthop Clin North Am 1976;7:231-40.

4. Staheli LT. Torsion: treatment indications. Clin Orthop Relat Res 1989;247:61-6.

5. Crane L. Femoral torsion and its relation to toeing-in and toeing-out. J Bone Joint Surg Am 1959;41-A:421-8.

6. Munuera PV, Castillo JM, Dominguez G, Lafuente G. Orthotic devices with out-toeing wedge as treatment for in-toed gait in children. J Am Podiatr Med Assoc 2010;100:472-8.

7. Fabry G, MacEwen GD, Shands AR Jr. Torsion of the femur: a follow-up study in normal and abnormal conditions. J Bone Joint Surg Am 1973;55:1726-38.

8. Rethlefsen SA, Healy BS, Wren TA, Skaggs DL, Kay RM. Causes of intoeing gait in children with cerebral palsy. J Bone Joint Surg Am 2006;88:2175-80.
9. LeVeau BF, Bernhardt DB. Developmental biomechanics: effect of forces on the growth, development, and maintenance of the human body. Phys Ther 1984; 64:1874-82.

10. Chadayammuri V, Garabekyan T, Bedi A, PascualGarrido C, Rhodes J, O'Hara J, et al. Passive hip range of motion predicts femoral torsion and acetabular version. J Bone Joint Surg Am 2016;98:127-34.

11. Salter RB. Role of innominate osteotomy in the treatment of congenital dislocation and subluxation of the hip in the older child. J Bone Joint Surg Am 1966;48: 1413-39.

12. Staheli LT, Duncan WR, Schaefer E. Growth alterations in the hemiplegic child: a study of femoral anteversion, neck-shaft angle, hip rotation, C.E. angle, limb length and circumference in 50 hemiplegic children. Clin Orthop Relat Res 1968;60:205-12.

13. Cibulka MT, Sinacore DR, Cromer GS, Delitto A. Unilateral hip rotation range of motion asymmetry in patients with sacroiliac joint regional pain. Spine 1998;23:1009-15.

14. Gelberman RH, Cohen MS, Desai SS, Griffin PP, Salamon PB, O'Brien TM. Femoral anteversion: a clinical assessment of idiopathic intoeing gait in children. J Bone Joint Surg Br 1987;69:75-9.

15. Svenningsen S, Terjesen T, Auflem M, Berg V. Hip rotation and in-toeing gait: a study of normal subjects from four years until adult age. Clin Orthop Relat Res 1990;251:177-82.

16. Fabry G, Cheng LX, Molenaers G. Normal and abnormal torsional development in children. Clin Orthop Relat Res 1994;302:22-6.

17. Uden H, Kumar S. Non-surgical management of a pediatric "intoed" gait pattern: a systematic review of the current best evidence. J Multidiscip Healthc 2012; 5:27-35.

18. Cibulka MT. Determination and significance of femoral neck anteversion. Phys Ther 2004;84:550-8.

19. Maenpaa H, Jaakkola R, Sandstrom M, Von Wendt L. Does microcurrent stimulation increase the range of movement of ankle dorsiflexion in children with cerebral palsy? Disabil Rehabil 2004;26:669-77.

20. Byl NN, McKenzie AL, West JM, Whitney JD, Hunt TK, Hopf HW, et al. Pulsed microamperage stimulation: a controlled study of healing of surgically induced wounds in Yucatan pigs. Phys Ther 1994;74:201-13. 
21. Kim MY, Kwon DR, Lee HI. Therapeutic effect of microcurrent therapy in infants with congenital muscular torticollis. PM R 2009;1:736-9.

22. Kwon DR, Park GY. Efficacy of microcurrent therapy in infants with congenital muscular torticollis involving the entire sternocleidomastoid muscle: a randomized placebo-controlled trial. Clin Rehabil 2014;28:983-91.

23. Shah SB, Peters D, Jordan KA, Milner DJ, Friden J, Capetanaki $Y$, et al. Sarcomere number regulation maintained after immobilization in desmin-null mouse skeletal muscle. J Exp Biol 2001;204:1703-10.

24. Clarren SK. Plagiocephaly and torticollis: etiology, natural history, and helmet treatment. J Pediatr 1981;98:92-5.

25. Kim HD, Lee DS, Eom MJ, Hwang JS, Han NM, Jo GY. Relationship between physical examinations and twodimensional computed tomographic findings in children with intoeing gait. Ann Rehabil Med 2011;35:4918.

26. Semciw AI, Green RA, Pizzari T, Briggs C. Verification of a standardized method for inserting intramuscular EMG electrodes into uniquely oriented segments of gluteus minimus and gluteus medius. Clin Anat 2013;26:244-52.

27. Inan M, Altintaş F, Duru I. The evaluation and management of rotational deformity in cerebral palsy. Acta Orthop Traumatol Turc 2009;43:106-12.

28. Li YH, Leong JC. Intoeing gait in children. Hong Kong Med J 1999;5:360-366.

29. Hewett TE, Torg JS, Boden BP. Video analysis of trunk and knee motion during non-contact anterior cruciate ligament injury in female athletes: lateral trunk and knee abduction motion are combined components of the injury mechanism. Br J Sports Med 2009;43:41722.

30. Kolber MJ, Hanney WJ. The reliability and concurrent validity of shoulder mobility measurements using a digital inclinometer and goniometer: a technical report. Int J Sports Phys Ther 2012;7:306-13.

31. Gordon AM, Huxley AF, Julian FJ. The variation in isometric tension with sarcomere length in vertebrate muscle fibres. J Physiol 1966;184:170-92.

32. Akai M, Shirasaki Y, Tateishi T. Electrical stimulation on joint contracture: an experiment in rat model with direct current. Arch Phys Med Rehabil 1997;78:405-9.

33. Gibson JN, Smith K, Rennie MJ. Prevention of disuse muscle atrophy by means of electrical stimulation: maintenance of protein synthesis. Lancet 1988;2:76770 .

34. Cheng N, Van Hoof H, Bockx E, Hoogmartens MJ, Mulier JC, De Dijcker FJ, et al. The effects of electric currents on ATP generation, protein synthesis, and membrane transport of rat skin. Clin Orthop Relat Res 1982;171:264-72.

35. Farmer SE, James M. Contractures in orthopaedic and neurological conditions: a review of causes and treatment. Disabil Rehabil 2001;23:549-58.

36. Akki A, Yang H, Gupta A, Chacko VP, Yano T, Leppo MK, et al. Skeletal muscle ATP kinetics are impaired in frail mice. Age 2014;36:21-30.

37. Fleischli JG, Laughlin TJ. Electrical stimulation in wound healing. J Foot Ankle Surg 1997;36:457-61.

38. Brown MD, Cotter MA, Hudlicka O, Vrbova G. The effects of different patterns of muscle activity on capillary density, mechanical properties and structure of slow and fast rabbit muscles. Pflugers Arch 1976;361:241-50.

39. Losel S, Burgess-Milliron MJ, Micheli LJ, Edington CJ. A simplified technique for determining foot progression angle in children 4 to 16 years of age. J Pediatr Orthop 1996;16:570-4.

40. Milliron M, Loesel S, Micheli L, Edington C. Comparison of methods for calculation of foot progression angle: 1036. Med Sci Sports Exerc 1992;24(5 Suppl):S173. 